\title{
Cuidado e transformação social: avaliação da implantação do plantão comunitário no Complexo da Funerária
}

\author{
João Eduardo Coin-Carvalho \\ Vera Helena Ostronoff \\ Universidade Paulista
}

\begin{abstract}
Resumo
A prática em Psicologia Social Comunitária solicita a instituição de ferramentas ajustadas às condições concretas de intervenção. Neste trabalho são discutidas ações psicossociais em uma comunidade de baixa renda de São Paulo realizadas a partir de um dispositivo de atendimento em grupo. Durante os anos de 2007 e 2008 foram conduzidos Plantões Comunitários, um grupo aberto e de participação espontânea tendo como referências a prática do Plantão Psicológico e os princípios teórico-políticos da Psicologia Social Comunitária. Em uma "roda de cadeiras" montada sobre a calçada, três psicólogos mediaram encontros semanais entre moradores. O Plantão Comunitário permitiu o acolhimento e o compartilhamento de experiências, assim como promoveu horizontalidade e empoderamento entre os participantes. Os resultados indicam a importância de dispositivos simples de encontro, desafiando os limites entre o público e o privado e justifica o desenvolvimento de práticas grupais inovadoras e críticas para ações psicossociais.
\end{abstract}

Palavras-chave: psicologia social; psicologia comunitária; comunidades; vulnerabilidade; grupos.

\begin{abstract}
Care and social change: The comunnity duty experience in funeraria complex. Community Social Psychology actions need practical tools that consider psychosocial, ethic, and politic dimensions. In this work we discuss a group device applied to a low income community in São Paulo City. During 2007 and 2008, Community Duty, an open and spontaneous participation group, happened weekly under the practical and theoretical principles of Psychological Duty and Community Social Psychology. On the sidewalk, an available wheel of chairs was arranged for three psychologists mediate people meetings. Community Duty offered shelter and the sharing of people experiences. As a politic device, it promoted people meetings and horizontal relationships, setting them as protagonists. Results suggest the importance of this kind of group device and defy the limits between public and private experience. Concluding, Community Duty suggests the importance of simple group devices, justifying the development of creative practices as social and health actions.
\end{abstract}

Keywords: social psychology; community psychology; community; vulnerability; groups.

\section{Resumen}

Cuidado e transformacion social: Evaluación de la implementacion delturno comunitário en el complexo de la funerária. Los trabajos en Psicología Social Comunitaria piden la introducción de herramientas adaptadas a las circunstancias locales de intervención. En este trabajo se discuten las acciones psicosociales en una comunidad de bajos ingresos en São Paulo, que se llevó a cabo a partir de un dispositivo de atención y cuidado. En los años 2007 y 2008 se realizaran Turnos Comunitarios, grupos abiertos y de participación espontánea, que toman como referencia los principios psicológicos y teórico-políticos de la Psicología Social Comunitaria. En una "silla de ruedas" montado en el pavimento, tres psicólogos mediaron reuniones semanales entre los residentes. El Turno Comunitario permitió experiencias de acogida y de intercambio, en una práctica que buscó horizontalidad y empoderamiento entre los participantes. Los resultados indican la importancia de proyectos simples, que desafían los límites entre público y privado, y justifica el desarrollo de prácticas innovadoras y críticas para las acciones psicosociales.

Palabras clave: psicología social; psicología comunitária; comunidade; vulnerabilidade; grupos.

$\mathrm{D}$ entro da tradição da psicologia social brasileira, trabalhos em Psicologia Social Comunitária tratam de processos no âmbito dos grupos, comunidades e instituições sobre os quais recaem as condições de exclusão social que não permitem o reconhecimento e a instalação de projetos coletivos (Sawaia, 2009). Conduzir intervenções que levem 
a ações transformadoras nestes cenários implica compreender não apenas aspectos técnicos, mas também as dimensões psicossocial e ético-política nas quais estão inseridos. Esta preocupação exige a procura das condições próprias dos grupos e comunidades, desde suas histórias e singularidades aos vícios no relacionamento com o setor público, como elementos necessários para o enfrentamento dos limites e possibilidades que caracterizam ações psicossociais.

As práticas que se pretendem transformadoras e que possam contribuir para o protagonismo das populações vulneráveis têm nas técnicas e procedimentos realizados com grupos um de seus principais fundamentos. Tomado em sua dimensão histórico-social, o grupo é - ou pode ser - o lugar do encontro, do debate, da diferença e da convergência, possibilidade de descoberta das potencialidades transformadoras (Martins, 2007). Entende-se que estas potencialidades não se encontram depositadas apenas nos indivíduos senão como efeito ideológico, ou seja, não são os sujeitos solitários, mas os coletivos é que são motores da transformação. Os dispositivos grupais, neste registro crítico e ético-político enquanto ação de polis (dos muitos), não desconsidera as dimensões próprias dos indivíduos, suas histórias, temores e anseios, a dinâmica das relações funcionais e afetivas que acontecem entre indivíduos que estão face a face (Pichón-Rivière, 2009). Assim, no trato das relações, estes dispositivos são a chave para a construção de projetos coletivos que visem à transformação das condições efetivas de vida das populações excluídas.

O lugar oferecido para a psicologia no cenário recente desenhado pelas políticas públicas de saúde e assistência social, contrariando o longo histórico de um cômodo distanciamento profissional das questões sociais que afligem cronicamente o país, aponta para a necessidade de recursos próprios da psicologia, em especial aqueles que dizem respeito ao trabalho com grupos e coletivos (Porto, 2010; Senra \& Guzzo, 2012), em consonância com os temas e preocupações presentes em outros países latino-americanos na aproximação com as políticas públicas (Inzunza \& Constanzo, 2009; Rodríguez, 2013). Para além da indicação mais direta da "multiplicação" do psicólogo que passa de profissional que atenda "um" para o que atende "muitos", trata-se de uma nova mirada do psicólogo para as questões que dificultam ou impedem a associação entre indivíduos. É também a possibilidade de buscar reconhecimento coletivo entre quem compartilha as mesmas situações de opressão e exclusão social, produtoras de um sofrimento nos indivíduos que tem como regra a manutenção deles nesta condição e não a sua superação (Sawaia, 2009). Neste sentido, em consonância com as políticas públicas, o trabalho com grupos deve oferecer recursos para ações, como o acolhimento e o encontro, que podem contribuir para a passagem transformadora dos indivíduos de recebedores de assistência para a de cidadãos de direito (Senra \& Guzzo, 2012).

Neste trabalho são descritas e discutidas ações de extensão desenvolvidas em uma comunidade de baixa renda da Zona Norte de São Paulo - o Complexo da Funerária - a partir da implantação de um dispositivo de atendimento psicossocial em grupo: o Plantão Comunitário.

\section{Método}

O Complexo da Funerária é um conjunto de comunidades de baixa renda situado na Zona Norte de São Paulo, onde vivem cerca de 30 mil pessoas. As casas ocupam uma grande área pública pertencente à Prefeitura que tem no seu centro geográfico um equipamento antes destinado ao suporte funerário do município. Diferentes histórias, lideranças e estratégias de ocupação (Ramos \& Carvalho, 2008) dão nome a estes pequenos bairros da periferia: Nova Curuçá, Nova Tietê, Cidade Nova, Vila São João, Funerária. A comunidade é atendida por serviços e equipamentos públicos de saúde (Unidade Básica de Saúde, Pronto Socorro, Programa Saúde da Família) e assistência social (Centros de Criança e Adolescente, Serviço de Assistência Social à Família) e educação (Escola Municipal, Creche), todos com suporte da Prefeitura Municipal de São Paulo.

Como parte dos trabalhos do Grupo de Pesquisa Psicologia e Saúde, desde 2003 são conduzidas atividades de pesquisa e extensão em parceria com as equipes dos programas municipais públicos de assistência social e saúde, e com grupos de moradores da comunidade. Estas práticas, que implicam conhecer, aprender com as comunidades e atuar em diferentes contextos (Carvalho, 2007; Ostronoff, Fávero, \& Baldin, 2008; Ramos \& Carvalho, 2006) têm se caracterizado por reconhecer a singularidade dos indivíduos e da dinâmica dos grupos sociais em situação de exclusão. Todas as atividades são realizadas sob os princípios éticos de pesquisa com seres humanos indicados pela Resolução 466/12 do Conselho Nacional de Saúde.

A partir de abril de 2007 passou-se a fazer um "plantão" semanal, em espaço aberto e público, para discutir na comunidade as necessidades de saúde mental e as dificuldades no lidar com o excesso de encaminhamentos para avaliação psicológica, produzidos pelas escolas e pela Unidade Básica de Saúde da região. Com isto surgiram os primeiros Plantões Comunitários, dispositivos grupais abertos e de participação espontânea oferecendo atendimento psicossocial à comunidade. Para registro, planejamento e discussão da experiência, relatórios referentes aos encontros foram produzidos ao longo de todo o período.

Nesta primeira fase, o Plantão Comunitário aconteceu durante os anos de 2007 e 2008, semanalmente, nas manhãs de sábado, com cerca de duas horas de duração, coordenado por três psicólogos. Sobre a calçada era montada uma roda de cadeiras que ficava disponível para aqueles que quisessem conversar, contar problemas, tirar dúvidas ou apenas escutar o que estava sendo tratado. Os participantes eram convidados a estabelecer suas próprias pautas, ritmos e compromissos, em encontros em que todos eram protagonistas. 


\section{Resultados e discussão}

\section{O plantão comunitário}

A instituição do Plantão Comunitário é antes uma história de incertezas, tentativas e dificuldades que o resultado de um planejamento sem desvios. A partir dos primeiros contatos com a comunidade logo na chegada dos trabalhos de extensão e pesquisa, professores e alunos tiveram que administrar desde a não familiaridade com os problemas da população até a desconfiança sobre o papel da Universidade ali. O trabalho com grupos mostrou os limites de uma ação transformadora que tinha como emblema a dificuldade crônica de instituir coletivos. Nas práticas em Psicologia Comunitária, junto com as lideranças da região, evitando uma ação voluntarista e assistencialista, foi possível expor os limites transformadores desta presença, conhecer e principalmente se deixar conhecer pelos moradores, assim como participar de mudanças e descobertas, mas não sem colecionar uma lista de insucessos e desencontros.

Sobre as dificuldades para agrupar a comunidade, as lideranças explicavam como o povo já "tem tudo": água, luz, telefone, coleta de lixo, "Casas Bahia"; vivem em casas de alvenaria; as ruas não inundam (tanto) mais; tem posto de saúde e hospital. Alertavam que é difícil que venham a se organizar por questões que alcançam a todos: violência, drogas, falta de áreas de lazer e árvores, melhoria do serviço de saúde. A desconfiança dos moradores era associada ao desvalor e ao controle social a que estão submetidos, mesmo as lideranças, reproduzindo a impotência de quem foi longa e intensamente submetido às condições sociais de miséria, sofrimento e humilhação (Das, 1997; Gonçalves Filho, 1998).

Dentro deste contexto, como parte das ações de extensão do curso de Psicologia da Universidade Paulista, ex-alunos e professores já haviam iniciado em 2006 um Plantão Psicológico, atendimento clínico e breve que tem sido praticado em instituições com a finalidade de possibilitar a quem o procura não só clarear a sua queixa e a situação problemática que vive, mas também a maneira de encaminhá-la. (Halpern-Chalom, 2001; Mahfoud, 1987; Morato, 1999; Souza \& Souza, 2011).

A iniciativa mostrou-se, depois de um ano de atendimentos a adultos, crianças e famílias, aquém das expectativas e necessidades da comunidade. Os moradores da comunidade que procuravam os psicólogos faziam-no levando-lhes seus "problemas psicológicos", encaminhados por médicos ou pelos professores. Os plantonistas, por sua vez, compactuavam com esta perspectiva convencional e curativa, uma vez que, em salas fechadas, e depois de fazerem uma ficha cadastral do "cliente", atendiam-nos ouvindo a queixa para, depois, procurarem o melhor encaminhamento a ser dado ao "caso". Desta forma, o plantão acabou se transformando muitas vezes numa experiência de triagem (Morato, 1999), privilegiando a escuta do "problema" individual, classificando-o, e dando-lhe encaminhamento psicoterapêutico ou diagnóstico para os (poucos) serviços de saúde mental da região. Além disso, a inexistência de um serviço público de atendimento psicológico na região acabou por construir uma demanda crescente e desproporcional, trazendo moradores até de outros municípios.

A impossibilidade de gerenciar um serviço de atendimento psicológico nestas condições e a inadequação de tal modelo de prática no contexto da comunidade solicitou uma nova abordagem que incluiu a perspectiva e as estratégias utilizadas nas ações de Psicologia Social Comunitária (Freitas, 1998; Lane \& Sawaia, 1995; Ximenes, Paula, \& Barros, 2009).

Ao invés de oferecer serviços, o "plantão" ofereceu de imediato a oportunidade de apontar (e criticar) de um lado a ausência ou inadequação da sua oferta pelo gestor público, mas de outro também a demanda de cura sobre questões que não podiam ser localizadas em indivíduos, mas que deveriam ser buscadas nas próprias instituições.

A junção das duas atividades teve resultado inesperado: produzir encontros, espaços para acolher, conversar e discutir "com o psicólogo", fora do registro do atendimento individual e privado. Inicialmente dentro da pequena igreja da comunidade, portas semicerradas; depois as portas escancaradas, como a convidar para entrar; e enfim no meio da rua, atrapalhando o caminho. Para a comunidade, houve uma mudança de paradigma da ação de ajuda/saúde; para os psicólogos, uma mudança de modelo de prática profissional.

Interrompendo o caminho e desafiando o entendimento do que seja o "trabalho do psicólogo", o Plantão ofereceu um espaço para sentar, ouvir, se queixar. Foi lugar de acolhimento e reflexão sobre as relações saúde-doença, os serviços de saúde oferecidos à população e o compartilhamento de experiências e soluções para questões de saúde e sociais em grupo, permitindo a reflexão e a discussão dos moradores, mediadas por psicólogos. Como dispositivo político, promoveu o encontro numa condição de horizontalidade entre os participantes.

\section{A instituição do grupo e o manejo de sua operativi- dade}

Pessoas no meio da rua, sentadas em roda, em cadeiras de plástico velhas, algumas desocupadas. Na frente da pequena igreja católica da comunidade, sob um sol escaldante, homens e mulheres conversam animados. A moradora se aproxima do grupo: "chamou a atenção o fato de ter gente diferente na rua". Ela se encantou com a imagem estranha, com o folguedo se desenrolando na calçada.

O Plantão Comunitário foi proposto como uma modalidade de atendimento em grupo, aberto e de participação espontânea. Os temas dos encontros não eram pré-estabelecidos, mas surgiam a partir das próprias demandas do grupo. A estranheza do grupo montado no meio da rua, no espaço público, se apresentou como um desafio ao modelo profissional e ao isolamento que marca a separação entre as esferas pública e privada. E isto tanto para os profissionais envolvidos quanto para os moradores da comunidade, que custam a entender o que aquele grupo de psicólogos pode fazer.

A importância do trabalho em grupo, nesta apresentação estranha e provocativa, esteve em não evocar experiências e imagens que pudessem manter os modelos hegemônicos e 
conservadores quanto à ação de saúde ou de assistência social. A estranheza frente ao grupo de psicólogos que atendiam juntos num espaço público fazia pensar que não se tratava do dispositivo tradicional de psicoterapia, nem de confessionário, sequer do mero desabafo. Poderia ser mais bem representada pela experiência do testemunho, tão comum em certas práticas religiosas, sem o temor da execração pública, da depuração através da expiação.

A estranheza esteve na própria possibilidade de encontrar outros, algo que escapa à experiência cotidiana fundada na individualidade e no confronto. O estranho é que esse acolhimento grupal pudesse ser ponto de partida para a associação entre indivíduos. A possibilidade de um encontro não burocrático nem funcional, mas solidário, é o que pavimenta o caminho da construção de projetos coletivos (Lane \& Sawaia, 1995), dos quais participam também os profissionais que fazem a mediação, apresentados não como provedores, consultores, nem sabedores, mas apenas os "mais um", interessados e engajados na elaboração destes projetos.

O formato de três ou quatro coordenadores que se revezam funcionou a favor da instituição do grupo através de sua imagem: mesmo antes dos participantes chegarem já havia ali pessoas conversando, tratando, buscando. A presença de profissionais também fez, desse, não um encontro qualquer: os psicólogos são, num primeiro momento, suposição de autoridade e saber, além de testemunho e compartilhamento. Acompanhando o desenrolar dos Plantões Comunitários, pode-se perceber que a instituição do grupo a cada vez dependeu, em grande parte, da formação deste núcleo atrator, a presença física dos psicólogos, num lugar que viria a fomentar encontros ao longo do tempo. Tempo para ver, para desconfiar, para notar a repetição, para se dar conta da estranheza. Os períodos de ausência do Plantão da comunidade - em se tratando de atividade acadêmica havia dificuldades para sustentá-la nos períodos de recesso e férias - seguiam inevitavelmente de um recrudescimento das presenças dos participantes, e na volta era preciso começar tudo novamente.

A caracterização do Plantão como um grupo aberto foi, neste sentido, facilitadora das retomadas, ainda que exigisse um manejo mais atento quanto à entrada e saída dos participantes, ao estabelecimento do enquadre e às múltiplas cenas que se desenrolavam ao longo dos encontros. No grupo aberto, o de fora é sempre o diferente, o novo que "perturba" e que precisa ser acolhido, o que neste caso vinha a se dar continuamente, solicitando do grupo uma maior disponibilidade e tolerância. Para o contrato, oferecido sempre e repetidamente dentro do grupo, a tarefa "falar tudo o que pode ser tratado em grupo, que pode ser ouvido no grupo", solicitou uma permanente negociação entre o que era privado e o que poderia ser público.

A presença de múltiplas cenas foi uma das circunstâncias que no trabalho se mostrou mais sensível: havia mais de uma em andamento ao longo de um encontro, seja porque pessoas estavam chegando e entrando para participar, querendo saber o que estava acontecendo, seja porque a presença de vários psicólogos chamava por conversas paralelas. Neste caso, estas outras cenas demandavam o manejo do coordenador para colocá-las sob a luz dos holofotes e fazê-las serem vistas, percebidas, girando a atenção de todo o grupo para este movimento de interferência e interação, entre cenas. Eventualmente, por ser um trabalho que acontecia no meio da rua, as cenas se davam também fora do grupo: um morador que cumprimenta quem está sentado na roda, alguém que, em pé, pergunta o que está acontecendo ali, uma criança que atravessa o grupo correndo.

O manejo no grupo pelos coordenadores apontou sistematicamente a possibilidade de escolhas, de participação e de associação. Não de escolhas simples sobre o futuro, mas de descobrir o futuro como engendramento coletivo, não como prática individual. Para isto foi preciso desafiar duas demandas espontâneas que o trabalho de atenção num contexto comunitário apresenta, inicialmente já instaladas, e que provocam a ação profissional estereotipada: a ação pública social de satisfação das faltas (o assistente social "assistencialista"); e o trabalho tradicional do psicólogo no atendimento individual (o psicólogo clínico "particular"). Atravessar estas demandas significou desafiar a imagem do trabalho com a comunidade através da sustentação do novo setting (na rua, grupos abertos) e da ação colaborativa (advocate) e integrada junto com a população - o profissional, ele também um participante da ação coletiva (Das, 1997). O Plantão Comunitário solicitou criar espaços de confiança, estabelecendo alvos coletivos, e, de certa forma, um espaço de tensão entre as subjetividades (expectativas, desconfianças, medos, sonhos, desejos, etc.), com os coordenadores atuando como facilitadores e fomentadores do grupo.

Importante registrar que, embora o Plantão tenha se realizado aparentemente de maneira descontraída, ele não foi descontração. Não se pode confundi-lo com um grupo de psicoterapia, de orientação, para distração e/ou catarse, pois na medida em que sua instituição pretendia transformar relações, horizontes e projetos, os encontros se pretenderam operativos (Pichón-Rivière, 2005). Seu manejo disponibilizou a possibilidade de encontro com outros, emblematicamente representados por um grupo de profissionais, mas empenhados em acompanhar o processo grupal.

\section{O plantão comunitário como prática de acolhimento e transformação}

A prática do Plantão Comunitário como apresentada aqui tem semelhanças importantes, nas suas pretensões, nas condições de aplicação e na aproximação com as políticas públicas, com outras práticas grupais, como a Terapia Comunitária, uma "prática terapêutica pós-moderna crítica" (Grandesso, 2007, p. 182) que vem sendo oferecida inclusive como ação complementar de saúde (Brasil, 2008). Como aquela, o Plantão promove dentro dos grupos acolhimento, constitui-se através de um ritual (a presença dos coordenadores, as cadeiras no mesmo lugar, a repetição) tem duração determinada. Ali também o encontro; a possibilidade de se falar e ser ouvido; os grupos são abertos e de participação espontânea. O Plantão, como a Terapia Comunitária, defende princípios inatacáveis como a 
justiça social, a autonomia dos grupos sociais, o respeito às especificidades culturais e de valor, seu empoderamento.

Seja na tradição de Paulo Freire, seja na de uma psicologia comunitária crítica e comprometida, ambas as práticas pretendem ser uma "prática de transformação social" (Grandesso, 2007; Lane \& Sawaia, 1995), mas para isto algumas preocupações alertadas na experiência do Plantão são decisivas quando se pensa nesta direção. Não se duvida da importância de se criar redes solidárias de fortalecimento de autoestima que colocam o terapeuta a serviço da consciência social transformadora e podem devolver as pessoas à condição de autoria (Grandesso, 2007). Mas a experiência do Plantão fundada nos princípios de uma prática engajada, coletiva e transformadora, indica que esta condição não é suficiente para a construção da crítica social e da mudança. O grande desafio é a plena inscrição do elemento político que vai embasar a mudança, político na sua acepção enquanto prática coletiva (Campos, 2007). A direção política, para além da ação assistencial, pode contribuir para suplantar estas práticas como ideológicas, no sentido de contribuírem para a manutenção do status quo, da dominação (mais sutil), da apropriação do corpo. O equívoco seria considerar que a efetivação dos encontros quer seja através do Plantão Comunitário ou da Terapia Comunitária produza por si só mudança, e entender que estas práticas são suficientes para esta transformação.

Numa outra direção, é preciso sublinhar um princípio que se mostrou caro ao funcionamento do Plantão: a transformação social não pode ser alicerçada em mudanças pessoais, individualizando a responsabilização pelo sucesso ou fracasso de uma empreitada. Recusam-se entendimentos ingênuos que vêm do senso comum, como "cada pessoa pode transformar sua história" ou "as pessoas mudam, a comunidade muda”. O que esteve em jogo no Plantão não foram as mudanças individuais, sem desmerecer sua importância, mas a procura de mudanças coletivas que exigem outro modelo de ação, que não aponta exclusivamente o sujeito nem tampouco a estrutura social. Neste registro, a mudança é a entrada numa outra grandeza onde não há a recuperação do perdido, nem o achado do ideal, mas algo novo, diferente, mas plausível, disponível como possibilidade inscrita no imaginário (Castoriadis, 1986) e que não se realiza senão a partir do exercício do encontro entre pessoas no Plantão.

O trabalho comunitário que se pretendeu com o Plantão quer fazer jus ao que se fez em Psicologia Comunitária desde a década de 1970 (Lane \& Sawaia, 1995), cujo alicerce encontra-se nas discussões sobre as práticas comunitárias dentro de uma psicologia crítica, especialmente aquelas baseadas no conceito de processo grupal (Lane, 1984; Martins, 2007). Deve-se reconhecer, no entanto, que no Plantão se oferece uma grande importância aos componentes que também são caros na definição do potencial desta e de outras práticas comunitárias: a atenção aos sujeitos, a escuta clínica, na acepção originária, entendida esta no Plantão não como modelo tradicional de diagnóstico e psicoterapia, mas como a atitude de debruçar-se sobre o sofrimento do sujeito para compreendê-lo (Lévy, 2001).
Neste sentido, vale indicar que outros trabalhos com grupos, que vêm sendo conduzidos no âmbito das políticas públicas de saúde mental e que ocupam o espaço de suporte e apoio, têm acontecido em ambientes mais bem estruturados, sob a guarda de instituições, e que buscam algumas das mesmas condições que suportaram o Plantão Comunitário: o encontro e a construção de um entendimento crítico da condição dos participantes. Seja em um ambulatório de saúde mental (Peretti, Martins, \& Guanaes-Lorenzi, 2013) ou entre um grupo de artesanato (Scardoelli \& Waidman, 2011), estas ações também confirmam a importância dos grupos para a construção de uma cidadania plena e as dificuldades trazidas pelo desafio da instituição de coletivos mesmo em circunstâncias mais protegidas e menos ameaçadoras do que encontrar, paradoxalmente, vizinhos no meio da rua.

\section{Conclusões}

Os resultados indicam que a possibilidade de encontro entre moradores a partir da sustentação de um dispositivo cotidiano simples como o bate-papo num banco de praça, interroga os limites entre público e privado, conhecimento científico e saber tradicional. O Plantão Comunitário se mostrou eventualmente um dispositivo bastante efetivo para o encaminhamento de questões comunitárias, para o encontro, para o compartilhar de dificuldades e soluções, para a descoberta da solidariedade e da competência para dar conta de demandas que exigem um saber que já se possui. Ele pôde servir como referência para a prática de atividades comunitárias que podem ser cotidianas, acontecerem à luz do dia, no meio da rua, entre vizinhos. A prática do Plantão atrelada ao compromisso com a transformação da sociedade indica a importância do manejo das condições simbólicas e imaginárias que sustentam as relações entre sujeitos e coletividades em situação de alta vulnerabilidade, e ganha importância como ação profissional que pode contribuir, no âmbito das políticas públicas, para a instituição de cidadãos de direito a partir de condições de exclusão e sofrimento.

\section{Referências}

Brasil. Ministério da Saúde. Departamento de Atenção Básica. (2008). O projeto da terapia comunitária na atenção básica. Brasília: Ministério da Saúde. Recuperado de http://dtr2004.saude.gov.br/dab/terapia_comunitaria. php.

Campos, G. W.S. (2007). Um método de análise e co-gestão de coletivos. São Paulo: Hucitec.

Carvalho, J. E. C. de (2007). How can a child be a mother? Discourse on teenage pregnancy in a Brazilian favela. Culture, Health and Sexuality, 9(2), 109120. doi: 10.1080/13691050600994448

Castoriadis, C. (1986). A instituição imaginária da sociedade. Rio de Janeiro: Paz e Terra.

Das, V. (1997). Language and body: Transactions in the construction of pain. In A. Kleinman, V. Das \& M. Lock (Orgs.), Social Suffering (pp. 67-91). Berkeley: University of California Press.

Freitas, M. F. Q. (1998). Inserção na comunidade e análise de necessidades: Reflexões sobre a prática do psicólogo. Psicologia, Reflexão e Crítica, 11(1), 175-189. doi: 10.1590/S0102-79721998000100011 
Gonçalves Filho, J. M. (1998). Humilhação social: Um problema político em psicologia. Psicologia USP, 9(2), 11-67. doi: 10.1590/S010365641998000200002

Grandesso, M. A. (2007). Terapia comunitária: Uma prática pós-moderna crítica - considerações teórico-epistemológicas. In M. R. Barreto \& M. A. Grandesso (Orgs.), Terapia Comunitária: Tecendo redes para a transformação social - saúde, educação e políticas públicas (pp. 181-89). São Paulo: Casa do Psicólogo.

Halpern-Chalom, M. (2001). Contar histórias e expressar-se: Aprendizagem significativa e plantão psicológico abrindo possibilidades para a clínica (Dissertação de Mestrado não publicada). Instituto de Psicologia, Universidade de São Paulo, São Paulo.

Inzunza, J. A., \& Constanzo, A. Z. (2009). Psicología comunitaria y políticas sociales en Chile. Psicologia e Sociedade, 21(2), 275-282. doi: 10.1590/ S0102-71822009000200015

Lane, S. T. M. (1984). O processo grupal. In S. T. M. Lane \& W. Codo (Orgs.), Psicologia social: O homem em movimento (pp. 78-98). São Paulo: Brasiliense.

Lane, S. T. M., \& Sawaia, B. B. (1995). La psicologia social comunitaria en Brasil. In E. Wiesenfeld \& E. Sanchez (Orgs.), Psicologia social comunitaria: Contribuciones latino-americanas (pp. 69-115). Caracas, Venezuela: Tropykos.

Lévy, A. (2001). Ciências clínicas e organizações sociais: Sentido e crise de sentido. Belo Horizonte: Autêntica/FUMEC.

Mahfoud, M. (1987). A vivência de um desafio: Plantão psicológico. In R. L. Rosenberg (Org.), Aconselhamento psicológico centrado na pessoa (pp. 7583). São Paulo: EPU, 1987.

Martins, S. T. F. M. (2007). Psicologia social e processo grupal: A coerência entre fazer, pensar e sentir em Sílvia Lane. Psicologia \& Sociedade 19(n. esp. 2), 76-80. doi: 10.1590/S0102-71822007000500022

Morato, H. T. P. M. (Org.). (1999). Aconselhamento psicológico centrado na pessoa: Novos desafios. São Paulo: Casa do Psicólogo.

Ostronoff, V. H., Fávero, C. B., \& Baldin, P. D. (2008). Uma experiência de supervisão em oficinas de criatividade. In C. M. B. Cupertino (Org.), Espaços de criação em psicologia: Oficinas na prática (pp. 77-94). São Paulo: Annablume.

Peretti, A. G., Martins, P. P. S., \& Guanaes-Lorenzi, C. (2013). O manejo de conversas sobre problemas sociais em um grupo de apoio. Psicologia e Sociedade 25(n. esp.), 101-110. doi: 10.1590/S0102-71822013000500012

Pichón-Rivière, E. (2009). Técnica dos grupos operativos. In O processo grupal (pp. 121-138). São Paulo: Martins Fontes.

Porto, F. (2010). Ação conjunta de psicólogos e assistentes sociais é essencial para a garantia da emancipação e do protagonismo social da população. Revista Diálogos7, 7-11. Recuperado de http://site.cfp.org.br/wp-content/ uploads/2012/03/OK_-_Dixlogos_ed_7_FINAL_-_BAIXA.pdf

Ramos, C., \& Carvalho, J. E. C. (2006). Uma proposta de trabalho com grupos e instituições. In C. Ramos, G. G. Silva \& S. Souza (Orgs.), Práticas psicológicas em instituições: Uma reflexão sobre os serviços-escola (pp. 450460). São Paulo: Vetor.

Ramos, C., \& Carvalho, J. E. C. (2008). Espaço e subjetividade: Formação e intervenção em psicologia comunitária. Psicologia e Sociedade, 20(2), 174180. doi: 10.1590/S0102-71822008000200004

Rodríguez, A. (2013). La co-gestión de políticas públicas sociales entre estado y sociedad civil. El aporte de la psicología social comunitaria a la construcción del diálogo entre actores diversos. Global Journal of Community Psychology Practice, 4(2). Recuperado de http://www.gjcpp.org/pdfs/rodriguezv4i2-20130701.pdf.

Sawaia, B. B. (2009). Psicologia e desigualdade social: Uma reflexão sobre liberdade e transformação social. Psicologia e Sociedade, 21(3), 364-372. doi: 10.1590/S0102-71822009000300010

Scardoelli, M. G. C., \& Waidman, M. A. P. (2011). “Grupo" de artesanato: Espaço favorável à promoção da saúde mental. Escola Anna Nery, 15(2), 291-299. doi: 10.1590/S1414-81452011000200011
Senra, C. M. G., \& Guzzo, R. S. L. (2012). Assistência social e psicologia: Sobre as tensões e conflitos do psicólogo no cotidiano do serviço público. Psicologia e Sociedade, 24(2), 293-299. doi: 10.1590/S0102-71822012000200006

Souza, B. N., \& Souza, A. M. (2011) Plantão psicológico no Brasil (1997-2009): Saberes e práticas compartilhados. Estudos de Psicologia (Campinas), 28(2), 241-249. doi: 10.1590/S0103-166X2004000300003

Ximenes, V. M., Paula, L. R. C., \& Barros, J. P. P. (2009). Psicologia comunitária e política de assistência social: Diálogos sobre atuações em comunidades. Psicologia Ciência e Profissão, 29(4), 686-699. doi: 10.1590/S1414 98932009000400004 
João Eduardo Coin-Carvalho, Doutor em Psicologia pelo Instituto de Psicologia da Universidade de São Paulo (IPUSP), Pós-doutor em Antropologia pela Johns Hopkins University, Baltimore, EUA, é professor Titular na Universidade Paulista (UNIP). Endereço para correspondência: Rua Japurá 55, apto 617, Bela Vista, São Paulo, SP, CEP 01319-030. Telefone: (11) 99411.0909. E-mail: joaocoin@yahoo.com

Vera Helena Ostronoff, Mestre em Psicologia Escolar e do Desenvolvimento Humano pelo Instituto de Psicologia da Universidade de São Paulo (IPUSP), é Professor Adjunto na Universidade Paulista (UNIP). E-mail: vhostronoff@yahoo.com.br 